\title{
Mercury 197 Chlormerodrin in the diagnosis of intraocular tumours
}

\author{
J. M. GAPPIN AND D. P. GREAVES \\ From Moorfields Eye Hospital and University College Hospital, London
}

Intraocular tumours continue to pose diagnostic problems which are not mitigated by the rarity of such cases in the experience of the ophthalmologist. Clinical examination and observation of the natural history of intraocular lesions do not always offer a definitive diagnosis, and laboratory and other tests are needed to provide further information. The successful application of radio-isotopes in the investigation of malignancy elsewhere in the body has invited their introduction into the realm of ophthalmology.

This paper reports our experience with ${ }^{197} \mathrm{Hg}$ Chlormerodrin whole eye scanning during the last 3 years. Our inconclusive results with ${ }^{131} \mathrm{I}$ diiodofluorescein prompted us to try this other compound, which has been successfully used in brain scanning (Greaves and Cappin, 1968). Since ${ }^{197} \mathrm{Hg}$ Chlormerodrin is a $\gamma$-emitter, a counter-probe may be placed directly in front of the eyes, an obvious advantage over the use of $32 \mathrm{P}$, which, by virtue of the limited penetrating power of its $\beta$ rays, requires the counter probe to be placed directly over the lesion. Sodee ( 1963 , i 964) first suggested the use of Chlormerodrin and his initial reports of its use for indicating the presence of intraocular tumours were encouraging.

\section{Methods and apparatus}

The present series of cases is divided into two groups according to the apparatus employed for the detection of the $\gamma$-emission. The scintillation probe in both groups comprised a thallium-activated sodium iodide crystal and photomultiplier within a steel sheath. To the front of the probe was attached an open lead cylinder $\mathrm{I} \mathrm{cm}$. in diameter and in length. In group I, the probe was connected to an Ekco ratemeter and in Group 2 to the more accurate Harwell 2000 series scaler. The night before the test, an intramuscular injection of $\mathrm{I} \mathrm{ml}$. Mersalyl was given to the patients to block renal uptake of the isotope. On the day of the test $500 \mu \mathrm{g}$. $197 \mathrm{Hg}$ Chlormerodrin was injected intravenously and readings were taken over a period of 8 hours, and again at 24 hours after the injection.

\section{Group I}

The average count rates were recorded over a period of 2 minutes on the Ekco ratemeter (time constant 30 sec.). The probe was successively placed in front of each eye and also against a fixed position on the forehead which acted as a reference point for background activity.

\section{Group 2}

Readings were taken over 3 to 6 periods each of 30 sec. The total count over each side was recorded on the Harwell scaler and the average total count per minute for each eye was calculated. 
Our final results (Tables $\mathrm{I}$ to $\mathrm{V}$ ) are expressed as a percentage differential count

$(\mathrm{Q})=\frac{\mathrm{A}-\mathrm{U}}{\mathrm{U}-\mathrm{F}} \times$ I oo per cent. $\quad\left[\right.$ The formula is derived thus $\left.\frac{(\mathrm{A}-\mathrm{F})-(\mathrm{U}-\mathrm{F})}{\mathrm{U}-\mathrm{F}} \times \operatorname{100}=\frac{(\mathrm{A}-\mathrm{U}) \text { I } 00}{\mathrm{U}-\mathrm{F}}\right]$,

where $\mathrm{A}$ is the average count per minute over the affected eye, $\mathrm{U}$ over the unaffected eye, and $\mathrm{F}$ over the forehead. A dash indicates the absence of a recording at the time interval. In the Harwell 2000 scaler series, the difference A-U has been analysed with the Student t-test and the levels of significance recorded in brackets. An estimate of the volume of the tumours was made from measurements taken from the preserved specimens.

\section{Results}

GROUP I

This included eight cases of histologically proven malignant melanoma. Of these, five 흥 cases out of six in which 24 -hr readings were taken showed a marked increase in uptake by the affected eye, $Q=\left(32.5 \pm 5^{\cdot I}\right.$ per cent. at $\left.24 \mathrm{hrs}\right)$. The uptake of the affected eye $\vec{\exists}$ was increased for all readings except in two cases, and a similar pattern was observed in $\%$ another case of clinically-diagnosed malignant melanoma, subsequently treated by radiotherapy. Two cases of orbital metastasis, one from carcinoma of the breast, and another of choroidal metastasis from bronchial carcinoma both showed a marked increased uptake on the affected side. Two cases with benign pathology of an inflammatory nature were examined. One had retinal haemorrhages, periphlebitis, and rubeosis iridis, and in this case all the readings from the affected eye showed a marked increase over those from the normal. The other was a case of choroiditis in which only the 24 -hr reading showed at increase. (Charts of these results are available on request.)

GROUP 2

The Harwell 2000 series scaler has permitted statistical analysis of our second group of cases. This series of 44 cases includes 23 of histologically proven malignant melanomas (Table I), one of proven metastatic carcinoma (Table I), seven with a clinical diagnosis of malignant melanoma (Table II), six with benign non-inflammatory lesions (Table IV), four with benign lesions in congested eyes (Table V), and three with normal eyes (Table III).

Table I demonstrates that eighteen $(78 \cdot 4$ per cent.) of 23 eyes with proven malignant melanoma showed significantly increased uptakes by the affected eye compared with the normal eye at $5 \mathrm{hrs}$ and afterwards $(\mathrm{P}<0 \cdot 05$ or less $)$, and often at the earlier readings. Of the other five malignant melanomas, two (Cases 20 and $2 \mathrm{I}$ ) had significantly increased $\delta$ uptakes for all except the 24-hr readings, and a third Case (I 9 ) showed an increased uptake only at $7 \mathrm{hrs}$. Of the remaining two cases, one showed an increased 24 -hr reading 9 (Case 23); in the other (Case 22) the early readings, though increased, were very scattered, $\frac{D}{0}$ thereby reducing their statistical significance. The case of secondary carcinoma (Case 24) showed highly significant readings at all intervals. Thus, together with the malignant 0 melanomas, nineteen $(79.2$ per cent.) of 24 cases of intraocular tumours gave a definite $\mathbb{O}$ positive result in the test, three had suggestive results, and two were inconclusive. In $\underset{\omega}{N}$ total, $9^{2}$ per cent. of the tests were informative.

Six clinically diagnosed malignant melanomas were examined before radiotherapy (Table II) and five $(83.5$ per cent.) showed significantly increased uptakes at $3 \mathrm{hrs}$ and $\stackrel{\mathscr{\Phi}}{\rightarrow}$ afterwards. The other (Case 6) showed no significant difference because of widely 
Table I 24 cases with histological diagnosis: 23 cases of malignant melanoma and one of secondary carcinoma. Percentage differential count $Q=\frac{A-U}{U-F} \times$ i oo per cent.

(Also ' $t$ '-test probability values $P$ )

\begin{tabular}{|c|c|c|c|c|c|c|c|c|c|}
\hline \multirow{2}{*}{$\begin{array}{l}\text { Case } \\
\text { no. }\end{array}$} & \multirow[b]{2}{*}{ Sex } & \multirow{2}{*}{$\begin{array}{l}\text { Age } \\
\text { (yrs) }\end{array}$} & \multicolumn{5}{|c|}{ Hours after injection of $\mathrm{Hg}^{197}$ Chlormerodrin } & \multirow{2}{*}{$\begin{array}{l}\text { Tumour } \\
\text { Site }\end{array}$} & \multirow{2}{*}{$\begin{array}{l}\text { Volume of } \\
\text { tumour }\left(\mathrm{mm}^{3}\right)\end{array}$} \\
\hline & & & I & 3 & 5 & 7 & 24 & & \\
\hline I & $\mathbf{M}$ & 47 & $+26 \cdot 0$ & - & $+33 \cdot 0(\cdot 001)$ & $+20 \cdot 0 \quad(\cdot 001)$ & $+14^{\circ} 0(\cdot 001)$ & PC & - \\
\hline 2 & $\mathbf{F}$ & 59 & $+26 \cdot 0$ & $-10 \cdot 0(\cdot 01)$ & - & $+24 \cdot 0 \quad(\cdot 001)$ & $+38 \cdot 0 \quad(\cdot 001)$ & AC CB & 830 \\
\hline 3 & $\mathbf{M}$ & 49 & $+9 \cdot 9$ & $+13.8(\cdot 01)$ & $+16 \cdot 2(\cdot 01)$ & $+33 \cdot 9(\cdot 00 \mathrm{I})$ & $+103 \cdot 0(\cdot 001)$ & AC CB & 375 \\
\hline 4 & $\mathbf{F}$ & 57 & $+4 \cdot 4$ & $+16 \cdot 0(2 \cdot 01)$ & - & $+23.9(\cdot 001)$ & - & PG & 586 \\
\hline 5 & $\mathbf{M}$ & 53 & $-18 \cdot 0$ & $+9 \cdot 0(\cdot I)$ & $+10 \cdot 0(\cdot 02)$ & $+14 \cdot 0(\cdot 01)$ & - & PC & 3,250 \\
\hline 6 & $\mathbf{M}$ & 63 & +9.5 & $-17 \cdot 7 \quad(\cdot 5)$ & $+15.5(\cdot 0 \mathrm{I})$ & $+50 \cdot 1 \quad(\cdot 05)$ & $+26 \cdot 2 \quad(\cdot 01)$ & PG & 1,464 \\
\hline 7 & $\mathbf{F}$ & 50 & +0.8 & $+9.6(\cdot 001)$ & $+9 \cdot 1 \quad(\cdot O I)$ & $+15.9(.01)$ & $+36 \cdot 0 \quad(\cdot 01)$ & PG & 1,490 \\
\hline 8 & $\mathbf{F}$ & 60 & $+13 \cdot 1$ & $+6 \cdot 6(\cdot 05)$ & $+16 \cdot 0(0.5)$ & $+20 \cdot 0 \quad(\cdot 02)$ & $+53.0 \quad(.05)$ & PG & 1,830 \\
\hline 9 & $\mathbf{F}$ & 45 & $+5 \cdot 1$ & - & $+12.4(\cdot 1)$ & $+5 \cdot 0(\cdot 5)$ & $+24 \cdot 0 \quad(\cdot 01)$ & PC & 126 \\
\hline 10 & $\mathbf{M}$ & 77 & - & $+24.5(\cdot 01)$ & $+42 \cdot 0(\cdot 0 I)$ & $+27 \cdot 9(\cdot 01)$ & $+126 \cdot 0 \quad(.001)$ & PG & 2,350 \\
\hline 11 & $\mathbf{M}$ & 50 & - & $+13.8(\cdot 01)$ & $+17 \cdot 2$ (.OI) & $+13.2(.01)$ & $+36 \cdot 5(\cdot 01)$ & PC & 1,050 \\
\hline 12 & $\mathbf{M}$ & 63 & 一 & $+28.4(\cdot 001)$ & $+43.5(\cdot 001)$ & $+24 \cdot 1 \quad(\cdot 00 \mathrm{I})$ & $+29 \cdot 0 \quad(\cdot 001)$ & $* * \mathrm{PC}$ & 130 \\
\hline 13 & $\mathbf{F}$ & 33 & - & $+38.0(\cdot 001)$ & $+16 \cdot 3(\cdot 01)$ & $+18 \cdot 4(\cdot 02)$ & $+36 \cdot 2) \cdot 001($ & Tris & 120 \\
\hline 14 & $\mathbf{M}$ & 54 & - & $-6 \cdot 9(\cdot 8)$ & $+10.5(.02)$ & $+11 \cdot 4(\cdot 01)$ & $+32 \cdot 0 \quad(\cdot 001)$ & CB & 840 \\
\hline 15 & $\mathbf{M}$ & 62 & 一 & $+5 \cdot 0(\cdot 8)$ & $+8 \cdot 9(\cdot 001)$ & $+5 \cdot 0(\cdot 05)$ & $+40 \cdot 0(\cdot 001)$ & PC & 750 \\
\hline 16 & $\mathbf{F}$ & 80 & - & $+9 \cdot 1 \quad(\cdot 001)$ & $+25.9(\cdot 001)$ & $+25.8(\cdot 001)$ & $+71 \cdot 5(\cdot 001)$ & PC & 1,320 \\
\hline 17 & $\mathbf{F}$ & 49 & - & $+10.2(\cdot 01)$ & $+20 \cdot 0 \quad(\cdot 01)$ & $+30.2(.001)$ & $+44 \cdot 0(\cdot 001)$ & PG & 1,220 \\
\hline 18 & $\mathbf{M}$ & 80 & $-2 \cdot 4$ & $+16 \cdot 0 \quad(\cdot 0 I)$ & $+35 \cdot 0 \quad(\cdot 05)$ & $+51 \cdot 0 \quad(\cdot 001)$ & - & CONJ. & 680 \\
\hline 19 & $\mathbf{M}$ & 52 & $+10 \cdot 2$ & $+5 \cdot I \quad(\cdot O I)$ & $+8 \cdot 3(\cdot 1)$ & + II $1 \cdot 0 \quad(\cdot 001)$ & $+3 \cdot 4(\cdot 1)$ & PG & 126 \\
\hline 20 & $\mathbf{M}$ & 47 & - & $+4 \cdot 3(\cdot I)$ & $+7.5(\cdot 01)$ & $+7 \cdot 0(\cdot 02)$ & $-5 \cdot 0 \quad(\cdot 8)$ & AC CB & 220 \\
\hline 21 & $\mathbf{M}$ & 24 & - & $9.7 \quad(\cdot 001)$ & $+8.2(\cdot 0 I)$ & - & $+4 \cdot 0(\cdot 1)$ & PG & 140 \\
\hline 22 & $\mathbf{M}$ & 57 & $+47 \cdot 0$ & $+25 \cdot 0 \quad(\cdot 5)$ & $+25 \cdot 0 \quad(\cdot 5)$ & $+5 \cdot 0(\cdot I)$ & - & PC & 90 \\
\hline 23 & $\mathbf{M}$ & 25 & -22 & $-16 \cdot 5 \quad(\cdot 5)$ & $-19.3(\cdot 5)$ & $-7.5(\cdot 5)$ & $+26 \cdot 0 \quad(\cdot 01)$ & PG & $I, 464$ \\
\hline 24 & $\mathbf{F}$ & 70 & $+2 \cdot 9$ & $+26.5(\cdot 05)$ & $+62 \cdot 0(\cdot 001)$ & $+34 \cdot 8 \quad(\cdot 0 \mathrm{I})$ & $+55 \cdot 2(\cdot 00 \mathrm{I})$ & $\begin{array}{l}\text { Second- } \\
\text { ary adeno- } \\
\text { carcinoma } \\
\text { choroid }\end{array}$ & $\begin{array}{l}5,609 \\
\text { of }\end{array}$ \\
\hline
\end{tabular}

PC Posterior choroid CB Giliary body.

AC Anterior choroid CONJ Conjunctival, involving globe

*** Recurrence after radiotherapy

Table II Clinical diagnosis of malignant melanoma ( 7 cases)

(Also 't-test' probability values $P$ )

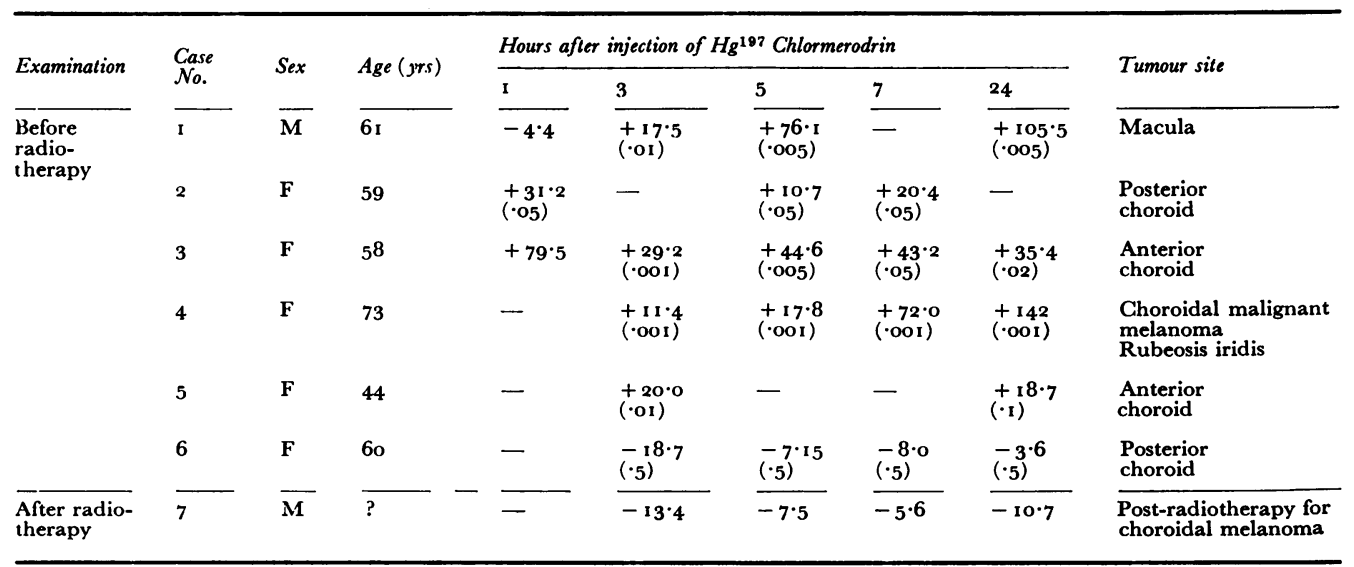


Table III Three normal eyes (Also 't-test' probability values $P$ )

Hours after injection of $\mathrm{Hg}^{197}$ Chlormerodrin

\begin{tabular}{|c|c|c|c|c|c|}
\hline Subject no. & I & 3 & 5 & 7 & 24 \\
\hline I & $\begin{array}{l}+3 \cdot 0 \\
(\cdot 1)\end{array}$ & $\begin{array}{l}+10.0 \\
(\cdot 5)\end{array}$ & $\begin{array}{l}-8 \cdot 0 \\
(\cdot I)\end{array}$ & $\begin{array}{l}-18 \cdot 0 \\
(\cdot 1)\end{array}$ & $\begin{array}{l}+0 \cdot 8 \\
(\cdot 8)\end{array}$ \\
\hline 2 & - & - & $\begin{array}{l}+0 \cdot 8 \\
(\cdot 5)\end{array}$ & $\begin{array}{l}+2 \cdot 0 \\
(\cdot 5)\end{array}$ & - \\
\hline 3 & +24.7 & $\begin{array}{l}-27 \cdot I \\
(\cdot I)\end{array}$ & $\begin{array}{l}-10.7 \\
(\cdot 5)\end{array}$ & - & $\begin{array}{l}+9.0 \\
(\cdot 25)\end{array}$ \\
\hline
\end{tabular}

Table IV Benign non-inflammatory lesions (6 cases) (Also 't-test' probability values $P$ )

Hours after injection of $\mathrm{Hg}^{197}$ Chlormerodrin

\begin{tabular}{|c|c|c|c|c|c|c|}
\hline Case no. & $\mathbf{I}$ & 3 & 5 & 7 & 24 & Lesion \\
\hline $\mathbf{I}$ & $\begin{array}{l}+22 \cdot 6 \\
(\cdot 01)\end{array}$ & $\begin{array}{l}+15 \cdot 7 \\
(\cdot 5)\end{array}$ & $\frac{-1 \cdot 3}{(\cdot 5)}$ & $\begin{array}{l}+6 \cdot 1 \\
(\cdot 5)\end{array}$ & $\begin{array}{l}-12 \cdot 1 \\
(\cdot 5)\end{array}$ & $\begin{array}{l}\text { Benign angle } \\
\text { naevus }\end{array}$ \\
\hline 2 & - & $-24 \cdot 8$ & $-27 \cdot 0$ & $-37 \cdot 0$ & -34.5 & Choroidal naevus \\
\hline 3 & -14.5 & $-19 \cdot 3$ & $-27 \cdot 5$ & $\begin{array}{l}-6 \cdot 5 \\
(\cdot 5)\end{array}$ & $\begin{array}{l}-9 \cdot 7 \\
(\cdot 5)\end{array}$ & $\begin{array}{l}\text { Chorio-retinal } \\
\text { exudates }\end{array}$ \\
\hline 4 & $-28 \cdot 6$ & $-31 \cdot 4$ & $-30 \cdot 0$ & $-1 \mathrm{I} \cdot 4$ & - & $\begin{array}{l}\text { Chorio-retinal } \\
\text { exudates }\end{array}$ \\
\hline 5 & - & $\begin{array}{l}+o \cdot 5 \\
(\cdot 8)\end{array}$ & $\begin{array}{l}+5 \cdot 5 \\
(\cdot I)\end{array}$ & $\begin{array}{l}+5 \cdot 6 \\
(\cdot 5)\end{array}$ & $\begin{array}{l}+2 \cdot 6 \\
(\cdot 5)\end{array}$ & $\begin{array}{l}\text { Chorio-retinal } \\
\text { exudates } \\
\text { Detachment }\end{array}$ \\
\hline 6 & - & $-14 \cdot 4$ & $-10 \cdot 8$ & $-15 \cdot 2$ & - & $\begin{array}{l}\text { Absolute glaucoma } \\
\text { Staphylomata }\end{array}$ \\
\hline
\end{tabular}

Table V Benign lesions of inflamed eyes (4 cases) (Also 't-test' probability values $P$ )

Hours after injection of $\mathrm{Hg}^{197}$ Chlormerodrin

\begin{tabular}{|c|c|c|c|c|c|c|}
\hline \multirow[b]{2}{*}{ Case No. } & & \multirow[b]{2}{*}{ Lesion } \\
\hline & $\mathbf{I}$ & 3 & 5 & 7 & 24 & \\
\hline I & $+9 \cdot 2$ & - & $\begin{array}{l}+28 \cdot 1 \\
(\cdot 01)\end{array}$ & $\begin{array}{l}-3 \cdot 7 \\
(\cdot 5)\end{array}$ & $\begin{array}{l}+22 \cdot 4 \\
(\cdot 02)\end{array}$ & $\begin{array}{l}\text { Exudative detachment } \\
\text { Uveitis } \\
\text { Sarcoidosis }\end{array}$ \\
\hline 2 & $+37 \cdot 4$ & $\begin{array}{l}+6 \mathrm{I} \\
(\cdot 0 \mathrm{I})\end{array}$ & $\begin{array}{l}+185 \\
(\cdot 01)\end{array}$ & $\begin{array}{l}+650 \\
(\cdot 001)\end{array}$ & $\begin{array}{l}+112 \\
(\cdot 01)\end{array}$ & $\begin{array}{l}\text { Rubeosis iridis } \\
\text { Vitreous baemorrhage } \\
\text { Aphakic detachment }\end{array}$ \\
\hline 3 & +37 & - & $\begin{array}{l}+46 \\
(\cdot 0 \mathrm{I})\end{array}$ & $\begin{array}{l}+48 \cdot 3 \\
(\cdot 0 \mathrm{I})\end{array}$ & $\begin{array}{l}+77 \cdot 4 \\
(\cdot 01)\end{array}$ & $\begin{array}{l}\text { Retinal haemorrhage } \\
\text { Rubeosis iridis }\end{array}$ \\
\hline 4 & - & $\frac{-16 \cdot 0}{(\cdot 02)}$ & $\begin{array}{l}-0 \cdot 4 \\
(\cdot 8)\end{array}$ & $\begin{array}{l}+15 \cdot 0 \\
(\cdot 01)\end{array}$ & $\begin{array}{l}+\mathrm{I} 7 \cdot 0 \\
(\cdot \mathbf{I})\end{array}$ & $\begin{array}{l}\text { Vitreous haemorrhage } \\
\text { Retinitis }\end{array}$ \\
\hline
\end{tabular}


scattered readings. To compare with the above cases of 'active' melanoma, the last (Case 7) was examined some 2 years after radiotherapy for a malignant melanoma which appeared to be clinically quiescent, and is still unchanged 5 years later. No increased uptake in the affected eye was recorded.

The control series (Table III) comprised three cases with completely normal eyes undergoing Chlormerodrin brain scans in whom further investigation failed to reveal the presence of intracranial tumours. No significant difference between the two eyes was demonstrated at any interval. Furthermore, no significant increase in uptake was found in the affected eyes of six patients with benign non-inflammatory pathology (Table IV). However, in four cases with benign pathology associated with gross congestion or inflammation, the affected eye registered pronounced increased uptakes as in the first series (Table V).

\section{Discussion}

Mercury 197 Chlormerodrin, which has been widely employed in brain and kidney scanning, offers many advantages (Sodee, I963; Rhoton, Carlsson, and Ter-Pogossian, I964; Takahashi, Nofal, and Beierwaltes, I966; Bollini and Tori, I964). It has a short half-life of $64 \mathrm{hrs}$ and the kidney and other essential organs absorb only a low dose of radiation, e.g. the kidney receives only $3.5 \mathrm{r}$ per mc. Chlormerodrin. Its rapid clearance from the body, (body half-life about $\mathrm{I} 5 \mathrm{hrs}$ ) reduces the background levels from the cavernous sinuses especially for the later readings of the test. With this compound Sodee (1963, 1964) reported a 90 per cent. relatively increased uptake of isotope in eyes containing tumours, but Leopold, Keates, and Charkes (i964) found a level of only 40 per cent. in one case out of nine. In only two of our cases did we obtain the levels of uptake similar to Sodee's, but different techniques of measurement were employed.

Our early experience with the ratemeter demonstrated a consistently increased uptake, albeit of variable degree, in seven out of eight tumour-bearing eyes, (Greaves and Cappin, I968). With the Harwell scaler an important advantage was obtained. This instrument summates the emitted particles (whose energy is selected by a pulse height analyser) by contrast to the ratemeter, which averages the emission over a chosen period. The count levels obtained in our second series were considerably higher and susceptible to statistical analysis.

Our continuing experience with this technique has amplified our previous report. In the present series nineteen out of 24 cases of proven intraocular tumour gave a definite positive result with a significantly increased uptake at 5 hours and afterwards, and a further three offered suggestive results, together making 92 per cent. Only in two cases were there false negatives. These may have been due to the small size of the tumour or to poor co-operation of the patient during the test with scattering of individual readings at each interval. Some movement of the head of the pat ent relative to the probe was almost certainly the cause of scattering in the three cases with suggestive results.

Significant results were obtained in five out of six cases of clinically diagnosed but not histologically verified melanoma. The results in the one false negative case were again marred by lack of patient co-operation. No significant difference in uptake between the eyes of normal patients and those of patients with quiet benign intraocular lesions could be demonstrated, and in the latter an affected eye might even show significantly lower uptakes 
than the normal eye. However, all inflamed eyes showed markedly elevated counts, thus producing false positive results, as other investigators have found when using radioisotope techniques. Leopold and others (I964) and Sodee (1963) utilized a focusing collimator, dividing the eye into octants and counting each segment individually. Leopold's measurements gave counts of the order of 100 and he did not achieve any success with this method. We also initially tried a narrow-beam focusing collimator, but as this did not give useful results we began recording whole eye counts with a large collimator; these counts were of the order of 5,000 to 8,000 per half minute at $7 \mathrm{hrs}$ and $\mathrm{I}, 500$ to 2,000 at $24 \mathrm{hrs}$.

It was not possible to correlate the levels of uptake with the type of tumour, its position, degree of necrosis, or vascularity. As already noted, there was a tendency for smaller tumours to show a lesser percentage of difference of uptake.

The incidence of positive results in brain scans employing ${ }^{197} \mathrm{Hg}$ Chlormerodrin is of a similar order to that in our own series, being about 85 per cent. for metastatic tumours, and possibly even higher for glioblastomas (Rhoton, Eichling, and Ter-Pogossian, I 966). Widely varying reports of $32 \mathrm{P}$ studies and their efficiency have been published. With a counter-probe in front of the globe, very poor results have been obtained with ${ }^{32} \mathrm{P}$, probably owing to the poor penetration of tissues by $\beta$ rays, and Leopold and others (1964) have summarized the results of several papers concerning these techniques. With a counterprobe placed behind the globe, some 89 per cent. of intraocular tumour-bearing eyes yielded positive results. Newell, Goren, Brizel, and Harper (1963) examined the ocular uptake of ${ }^{125} \mathrm{I}$ diiodofluorescein in a series of cases and obtained fifteen positive results from nineteen patients (79 per cent.; these workers reported no false positive results in a further series of twenty cases with non-inflammatory benign ocular conditions. In our earlier series of seven patients (Greaves and Cappin, 1968), we were unable to obtaine similar results with this technique.

Though many papers have recently been published demonstrating supposedly characteristic fluorescein angiographic features of choroidal malignant melanomas, few give any indication of the accuracy of the method in helping to substantiate the clinical diagnosis. Furthermore, the angiographic criteria for distinguishing between malignant melanomas and haemangiomas are not rigid. Pettit, Barton, Foos, and Christensen (1970) found a characteristic fluorescence pattern in 31 out of 36 cases of malignant melanomas (86 per cent.). Our results with Chlormerodrin compare favourably with this and the results obtained with other isotopes.

In addition to the facility with which the test can be performed, Tenon's capsule need not be opened to enable a probe to be passed behind the globe, nor is there need for such accurate positioning of the probe as is required for the ${ }^{32} \mathrm{P}$ test. There is the added advantage that our test can also be used for eyes with opaque media when fluorescein angiography is obviously precluded and $32 \mathrm{P}$ testing is difficult to perform with accuracy.

There are few laboratory techniques which can offer absolute confirmation of a clinically established diagnosis, and even these are only valuable under rigidly defined conditions. Our technique will distinguish between benign and malignant intraocular tumours in the majority of cases provided that inflammation is not present to mask the results.

Future developments in this field will necessitate a deeper understanding of tumour metabolism and the choice of compounds or specific metabolites appropriately labelled. We are currently engaged in investigating the diagnostic potentialities of other isotopically labelled compounds. 


\section{Summary}

Eye scanning was performed on two groups of patients who had received intravenous ${ }^{197} \mathrm{Hg}$ Chlormerodrin.

In the first series, five out of six patients with histologically proven malignant melanoma, two cases of ocular metastasis, and one case of clinically diagnosed malignant melanoma, all showed a marked increase in uptake in the affected eye compared with the normal. Two patients with inflammatory benign lesions also showed an increased uptake in the affected eye. In the second series, 79.2 per cent. of histologically proven intraocular tumours and 83.5 per cent. of clinically diagnosed malignant melanomas gave definitely positive tests. One case of previously treated clinically quiescent malignant melanoma, three subjects with normal eyes, and six patients with benign non-inflammatory lesions yielded negative tests. Four patients with benign inflammatory lesions produced false positive results.

We gratefully acknowledge the assistance of our colleagues at Moorfields and other hospitals who have graciously allowed us to investigate their patients and especially the considerable technical advice and assistance of the Physics Department of University College Hospital.

\section{References}

Bollini, v., and tORI G. (1964) In "Medical Radioisotope Scanning: Proc. Symp. Med. Rad.

Scanning, Athens, 1964, vol. 2, p. 257

GREAVES, D. P., and CAPPIN, J. M. (1968) Proc. roy. Soc. Med., 6r, I037

LEOPOLD, I. H., KEATES, E. U., and GHARKES, I. D. (1964) Trans. Amer.ophthal. Soc., 62, 86

NeWell, f. W., Goren, S. B., Brizel, H. E., and harper, P. v. (1963) Trans. Amer. Acad. Ophthal.

Otolaryng., 67, I 77

PetTit, T. H., Barton, A., Foos, R. Y., and Ghristensen, R. E. (1970) Arch. Ophthal. (Chicago), 83, 27 rhoton, A. L., Carlsson, A. M., and ter-pogossian, m. m. (1964) Arch. Neurol., 10, 369

- Eichling, J., and ter-Pogossian, M. M. (I966) $\mathcal{7}$. nucl. Med., 7, 50

SODEE, D. B. (1963) Ibid., 4, 335

- (1964) In "Medical Radioisotope Scanning: Proc. Symp. Med. Rad. Scanning, Athens, 1964", vol. 2, p. 147. International Atomic Energy Agency, Vienna.

TAKAHASHI, M., NOFAL, M. M., and BeIERWALtes, w. H. (I966) J.nucl. Med., 7, 32 